\title{
ANALISE E PROJETO DE HIDROCICLONES PARA O PROCESSAMENTO DE LODO PROVIDO DA INDÚSTRIA TÊXTIL
}

\author{
A.D. de MOURA ${ }^{1}$, T.R. MOURA ${ }^{1}$ e A.R.F. de ALMEIDA ${ }^{1,2}$ \\ ${ }^{1}$ Universidade Federal do Pampa, Programa de Pós-Graduação em Engenharias \\ ${ }^{2}$ Universidade Federal do Pampa, Curso de Engenharia Química \\ E-mail para contato: andre.almeida@unipampa.edu.br
}

\begin{abstract}
RESUMO - O objetivo deste trabalho foi projetar e analisar hidrociclones do tipo Rietema e Bradley para o espessamento de lodo produzido em indústrias têxteis. Para tal, efetuou-se, primeiramente, a caracterização física do lodo aonde foram obtidos dados experimentais da massa específica, da viscosidade, da concentração de sólidos e da distribuição do tamanho médio de partículas. Com os dados físicos do efluente, efetuou-se o projeto dos hidrociclones com o uso de equações propostas na literatura. Por fim, os hidrociclones projetados foram avaliados através de uma análise de sensibilidade paramétrica. Nesta análise foram alteradas tanto as variáveis de processo como as propriedades físicas do efluente, visando sempre à verificação da eficiência de separação do sistema. Os resultados obtidos mostraram que ambos os hidrociclones projetados neste estudo podem ser uma alternativa atrativa para o espessamento de lodo provido da indústria têxtil.
\end{abstract}

\section{INTRODUÇÃO}

Nos dias atuais, o descarte de efluentes industriais em rios, açudes, mananciais é bastante preocupante e vem sendo temática de fiscalizações bastante rigorosas pelos órgãos ambientais. Para Mihelcic e Zimmerman (2012) a poluição em sistemas aquosos se dá a partir de fontes pontuais, como o caso de descartes de lodos industriais por meio de tubulações, e a partir de fontes não pontuais, como o escoamento superficial de água de chuva e transferência da atmosfera para o sistema aquático.

Segundo Azevedo (2010), a indústria têxtil tem uma grande contribuição na geração de poluentes que quando não são devidamente tratados se tornam agravante problema ambiental. Uma das matérias primas da indústria têxtil é a lã de ovinos, onde, segundo Flores (2014), o Rio Grande do Sul, tem grande destaque na sua produção, sendo o maior produtor do país. Devido às condições como são criadas as ovelhas, o processamento industrial dessa lã é indispensável e consiste da retirada da maior parte possível de impurezas por meio da lavagem, para então ser transformada em fio pelo processo de cardar e por fim ser fiada e tingida.

Embora todo o processo de tratamento da matéria prima, desde a criação do ovino até o tingimento apresente geração de efluente, o maior percentual se dá no processo de lavagem e 
tingimento (Tunay et.al; 1996). Nesses processos os componentes de destaque contidos no efluente são proteínas, amidos, gorduras e corantes. Além disso, a alta temperatura e pH que são utilizados na lavagem contribuem significativamente para a geração dos lodos como efluente e a alta quantidade de água utilizada faz com que este efluente fique bastante úmido. Azevedo (2010) relata que apesar de existir diversas formas de tratamentos fundamentados em princípios físico-químicos, uma maneira de tratar esse efluente pode ser por meio de decantação ou sedimentação através de tratamento biológico via sistema de lodos ativados. Porém, apesar de apresentar uma boa eficiência, não é suficiente para remoção de compostos orgânicos dissolvidos, além de ser bastante suscetível à composição do efluente e produzir grande volume de lodo. Outras opções são a secagem ou hidrociclonagem.

Os hidrociclones, conforme mostra a Figura 1, são formados por uma parte cilíndrica superior, que é proporcional a capacidade de processamento, e uma parte cônica, que é responsável pela eficiência de coleta de sólido. Pode ser observado o diâmetro da parte cilíndrica $D_{\text {c }}$, diâmetro de alimentação $D_{\mathrm{i}}$, os diâmetros de overflow, $D_{o}$ e underflow, $D_{u}$, o ângulo $\theta$ da parte cônica, a altura da parte cilíndrica $L_{l}$, altura total $L$, e altura da secção de overflow, denominada córtex finder, $l$.

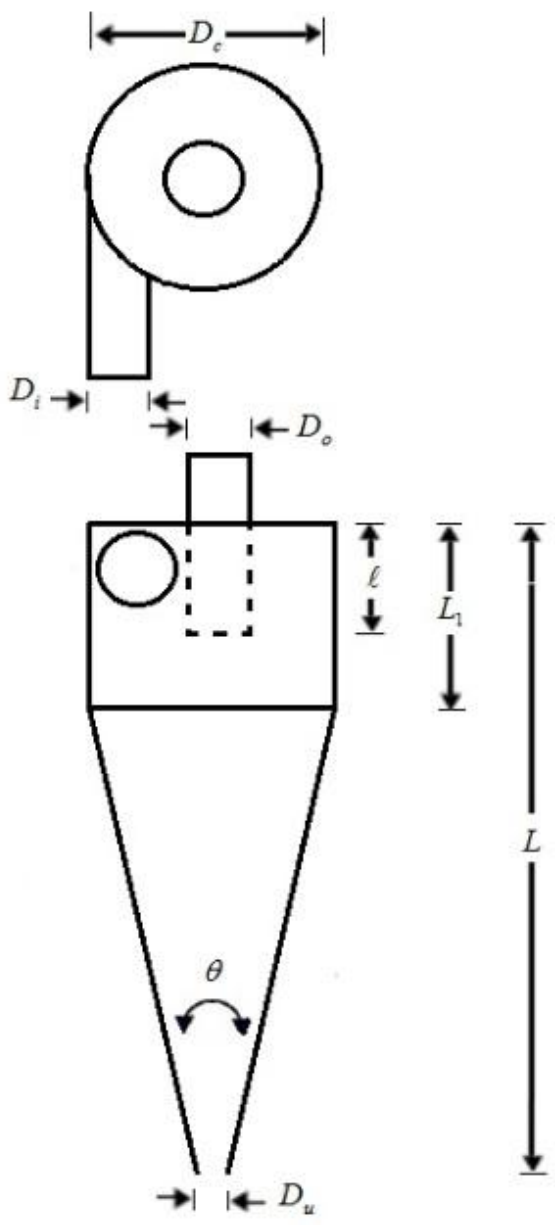

Figura 1 - Dimensões do hidrociclone, (Massarani, 2002). 
Segundo Cremasco (2012), na entrada do hidrociclone a mistura adquire movimento em espiral que se estendem até a base, os sólidos se direcionam a parede do equipamento que por sua vez age na direção radial, impondo movimento circular com trajetória helicoidal e assim saindo pelo coletor de sólidos (underflow). Enquanto que a fase líquida ascende, também em movimento espiral, porém circundando o eixo central até o duto de saída do fluido (overflow). Atuam sobre a trajetória helicoidal as forças de arraste, da gravidade e de atrito e sobre o escoamento em espiral as componentes das velocidades tangencial, axial e radial. Os parâmetros geométricos dos hidrociclones dependem da família a qual ele pertence. Segundo Massarani (2002) os hidrociclones da família Rietema e Bradley são os que aparecem com mais frequência nos trabalhos da literatura.

Como o Rio Grande do Sul apresenta um destaque na indústria têxtil brasileira, o objetivo desse trabalho foi projetar e analisar hidrociclones do tipo Rietema e Bradley para o espessamento do lodo produzido em uma indústria têxtil da cidade de Bagé/RS.

\section{MATERIAIS E MÉTODOS}

O lodo utilizado para o desenvolvimento deste estudo foi obtido junto a uma indústria têxtil da cidade de Bagé/RS. A caracterização física desse efluente foi feita através da obtenção da massa específica da fase fluida $(\rho)$ e da parte sólida $\left(\rho_{s}\right)$, ambos pela técnica da picnometria, da sua viscosidade $(\mu)$, com o uso de um viscosímetro do tipo copos FORD, da sua concentração de sólidos $\left(C_{v}\right)$, pela técnica de estufa a $105{ }^{\circ} \mathrm{C}$, e da sua distribuição do tamanho médio de partículas $\left(d_{p}\right)$ com uso da elutriação. O elutriador utilizado contém um tubo cilíndrico de $2,7 \mathrm{~cm}$ de diâmetro e $30 \mathrm{~cm}$ de altura. A Figura 2 mostra uma fotografia ilustrativa do elutriador e de todos os sistemas periféricos utilizados na elutriação, como a bomba peristáltica e a bomba de pressão.

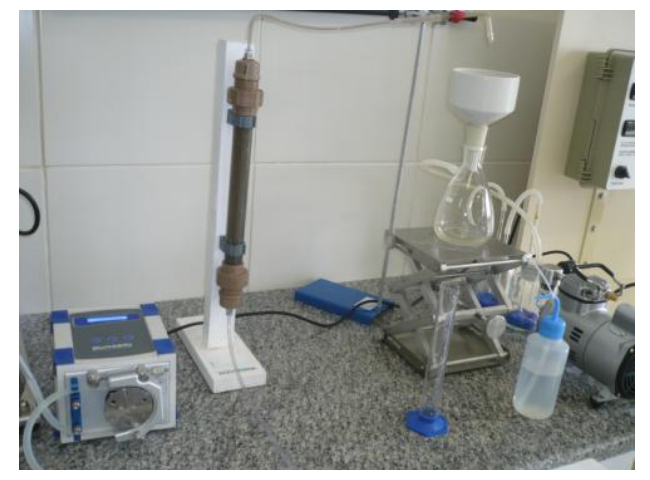

Figura 2 - Sistema de elutriação

A eficiência individual de coleta $(\eta)$ dos hidrociclones do tipo Rietema e Bradley, relativa ao diâmetro médio das partículas $\left(d_{p}\right)$ e do diâmetro de corte $\left(D^{*}\right)$ foi expressa pela relação empírica da Equação 1 (Massarani; 2002): 
$\eta\left(\frac{d_{p}}{D^{*}}\right)=\frac{\exp \left(5 d_{p} / D^{*}\right)-1}{\exp \left(5 d_{p} / D^{*}\right)+146}$

onde fixando um valor para $\eta$ e conhecendo o $d_{p}$, calculou-se o valor do $D^{*}$. Conhecendo o valor do $D^{*}$, foi possível obter o valor do diâmetro da parte cilíndrica dos hidrociclones $\left(D_{c}\right)$ com o uso das Equações 2 - 5, também propostas por Massarani (2002).

$\frac{D^{*}}{D_{c}}=K\left[\frac{\mu D_{c}}{Q\left(\rho_{s}-\rho\right)}\right]^{\frac{1}{2}} \cdot f\left(R_{L}\right) \cdot g\left(C_{v}\right)$

$f\left(R_{L}\right)=1+A R_{L}$

$R_{L}=B\left(D_{u} / D_{c}\right)^{C}$

$g\left(C_{v}\right)=\frac{1}{\left[4,8\left(1-C_{v}\right)^{2}-3,8\left(1-C_{v}\right)\right]^{0,5}}$

Na Equação 2, $Q$ corresponde a vazão de alimentação da fase fluida na entrada do hidrociclone, $f\left(R_{L}\right)$, obtido pela Equação 3, é um fator de correção que leva em conta o fato que uma fração das partículas sólidas é coletada no underflow sem a ação do campo centrífugo e está relacionado ao quociente entre as vazões de fluido no underflow e na alimentação $R_{L}$, sendo $R_{L}$ calculado com o uso da Equação 4. Também na Equação 2, o termo $g\left(C_{v}\right)$, que é obtido através da Equação 5, é um fator que leva em conta a concentração volumétrica $C_{v}$ na alimentação. Os termos $k, A, B$, e $C$ das Equações 2 - 4 são parâmetros tabelados para cada família de hidrociclones, onde seus valores podem ser encontrados em Massarani (2002).

Com o valor de $D_{c}$, os hidrociclones foram projetados com o auxílio das relações propostas na Tabela 1 .

Tabela 1 - Propriedades das famílias de hidrociclones (Massarani; 2002)

\begin{tabular}{ccccccc}
\hline Família & $D_{i} / D_{c}$ & $D_{o} / D_{c}$ & $L / D_{c}$ & $L_{l} / D_{c}$ & $l / D_{c}$ & $\theta$ \\
\hline Rietema & 0,28 & 0,34 & 5 & - & 0,40 & $10^{\circ}-20^{\circ}$ \\
Bradley & $1 / 7$ & $1 / 5$ & - & $1 / 2$ & $1 / 3$ & $9^{\circ}$ \\
\hline
\end{tabular}

Com os dados de projeto dos hidrociclones, efetuou-se uma análise da sensibilidade paramétrica através da observação da eficiência de coleta dos hidrociclones frente a variações na $Q, \rho_{s}, C_{v}$ e $d_{p}$. Também se efetuou uma análise da queda de pressão nos hidrociclones $(\Delta P)$ frente a variações na vazão de alimentação $(Q)$ para regime turbulento. Para essa análise foi utilizada as Equações 6 e 7, propostas por Massarani (2002). Nas Equações 6 e $7 u_{c}$ corresponde a velocidade média na seção cilíndrica.

$\beta=\frac{-\Delta P}{\rho u_{c}^{2} / 2}$ 
$u_{c}=\frac{4 Q}{\pi D_{c}^{2}}$

\section{RESULTADOS E DISCUSSÕES}

Na Figura 3 é apresentada uma fotografia ilustrativa do lodo caracterizado fisicamente neste trabalho, cujos dados experimentais obtidos encontram-se na Tabela 2.

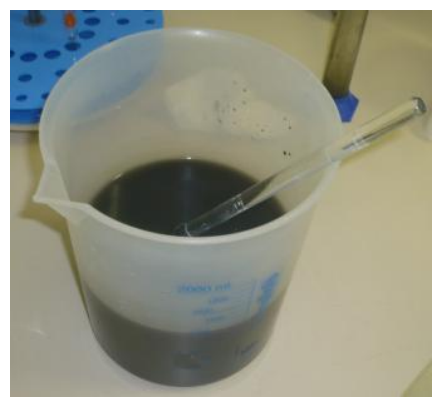

Figura 3 - Efluente de indústria têxtil.

Tabela 2 - Resultado da caracterização física e granulometria

\begin{tabular}{cccc}
\hline$\rho\left(\mathrm{kg} / \mathrm{m}^{3}\right)$ & $\rho_{s}\left(\mathrm{~kg} / \mathrm{m}^{3}\right)$ & $C_{v}(\%)$ & $d_{p}(\mu \mathrm{m})$ \\
\hline 1034,76 & 1002,64 & 4,02 & 586,15 \\
\hline
\end{tabular}

Observa-se na Tabela 2 que $\rho$ é bastante próxima a $\rho_{s}$. Esta proximidade pode ser um aspecto negativo para a eficiência de separação dos hidrociclones, visto que o princípio de separação do equipamento se dá pela ação da força centrípeta. Em relação a $C_{v}$, é verificado que o lodo encontra-se em uma fase bastante diluída. Este resultado mostra a importância da utilização dos hidrociclones para o espessamento do material. Para $d_{p}$ o valor encontrado foi de aproximadamente $586 \mu \mathrm{m}$, onde para uma melhor visualização da dimensão da parte sólida contida no lodo é apresentada na Figura 4 as curvas da distribuição do tamanho médio de partículas que foram obtidas com o auxílio da elutriação.

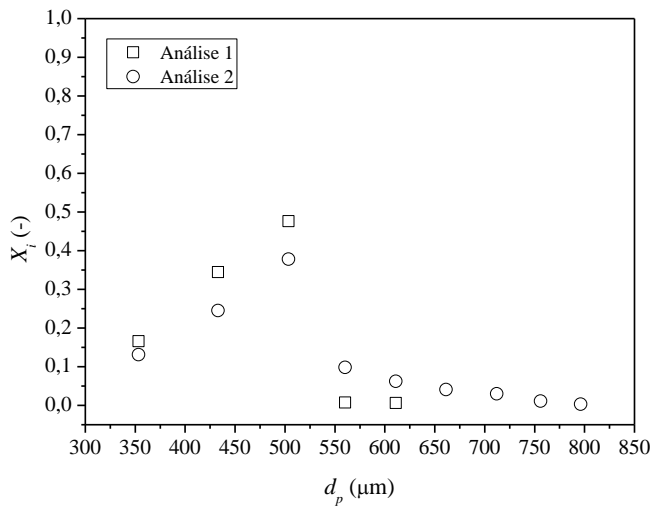

Figura 4 - Distribuição do tamanho médio de partículas do efluente da indústria têxtil.

Observa-se na Figura 4 que as partículas do efluente da indústria têxtil apresentam um 
comportamento típico de distribuição granulométrica diferencial, com formato de curva de distribuição normal (Foust et al.; 1982). Para as análises 1 e 2 aproximadamente $40 \%$ dos sólidos apresentaram um diâmetro de partícula de $500 \mu \mathrm{m}$.

Na Tabela 3 é apresentado os valores $R_{L} f\left(R_{L}\right)$ e $g\left(C_{v}\right)$ obtidos para os hidrociclones do tipo Rietema e Bradley operando em uma vazão de alimentação $(Q)$ de $0,014 \mathrm{~m}^{3} / \mathrm{s}$.

Tabela 3 - Valores $R_{L} f\left(R_{L}\right)$ e $g\left(C_{v}\right)$ calculados para os hidrociclones Rietema e Bradley.

\begin{tabular}{cccccc}
\hline \multicolumn{3}{c}{ Rietema } & \multicolumn{3}{c}{ Bradley } \\
\hline$R_{L}$ & $f\left(R_{L}\right)$ & $g\left(C_{v}\right)$ & $R_{L}$ & $f\left(R_{L}\right)$ & $g\left(C_{v}\right)$ \\
0,069 & 1,120 & 1,1365 & 0,167 & 1,288 & 1,1360 \\
\hline
\end{tabular}

Observa-se na Tabela 3 que a razão de líquido $\left(R_{L}\right)$ no hidrociclone do tipo Rietema é menor que a encontrada no hidrociclone do tipo Bradley. Isso indica que hidrociclone do tipo Rietema possui uma capacidade maior para o espessamento do lodo, pois quanto menor for o valor de $R_{L}$ menor é quantidade de líquido saindo no underflow (Massarani; 2002).

Na Tabela 4 é apresentado os valores das dimensões características dos hidrociclones do tipo Rietema e Bradley projetados neste trabalho, tendo como base os valores $R_{L}, f\left(R_{L}\right)$ e $g\left(C_{v}\right)$ calculados e apresentados na Tabela 3 e uma eficiência individual de coleta $(\eta)$ de $80 \%$.

Tabela 4 - Dimensões dos hidrociclones tipo Rietema e Bradley projetados

\begin{tabular}{ccccccc}
\hline Família & $D_{c}(\mathrm{~cm})$ & $D_{i}(\mathrm{~cm})$ & $D_{o}(\mathrm{~cm})$ & $L(\mathrm{~cm})$ & $L_{1}(\mathrm{~cm})$ & $l(\mathrm{~cm})$ \\
\hline Rietema & 8,10 & 2,27 & 2,75 & 40,5 & - & 3,24 \\
Bradley & 13,37 & 1,91 & 2,67 & - & 6,68 & 4,46 \\
\hline
\end{tabular}

Observa-se na Tabela 4 que os hidrociclones projetados apresentam diferenças significativas nas suas dimensões características, principalmente no valor de $D_{c}$. Para essa dimensão o hidrociclone do tipo Rietema apresentou um valor de aproximadamente 1,6 vezes menor que o encontrado para o hidrociclone do tipo Bradley.

Nas Figuras $5(\mathrm{a}-\mathrm{d})$ são apresentados os resultados obtidos na análise de sensibilidade paramétrica dos hidrociclones projetados.

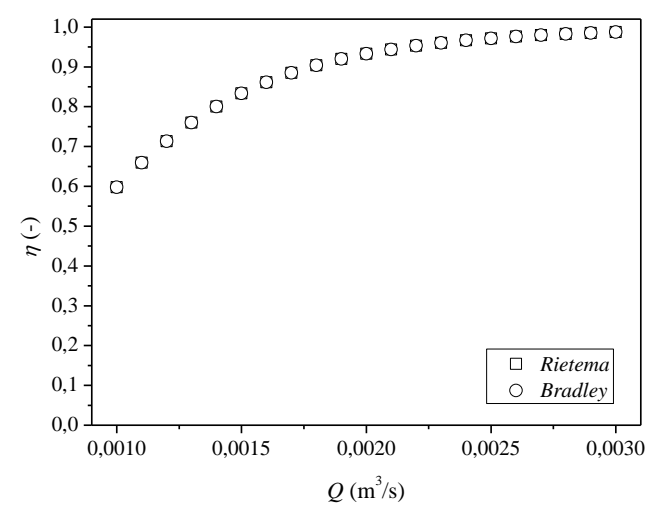

Figura 5 (a) - Eficiência de coleta em função da vazão de alimentação.

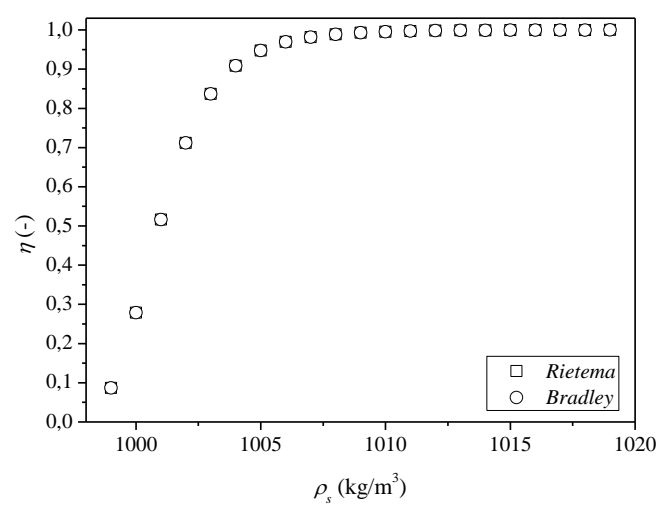

Figura 5 (b) - Eficiência de coleta em função da massa específica do sólido. 


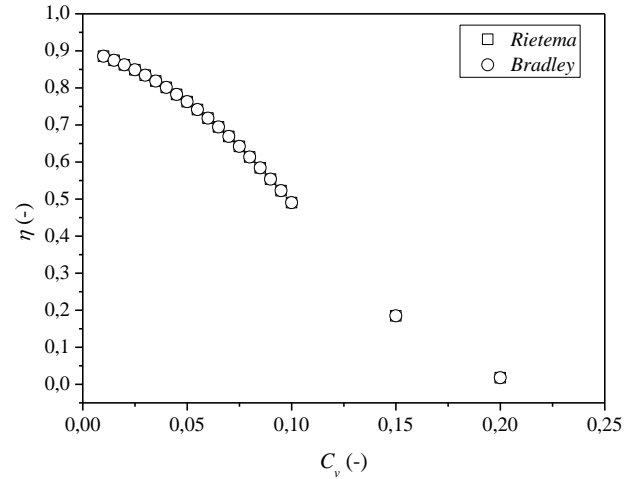

Figura 5 (c) - Eficiência de coleta em função da concentração de sólido.

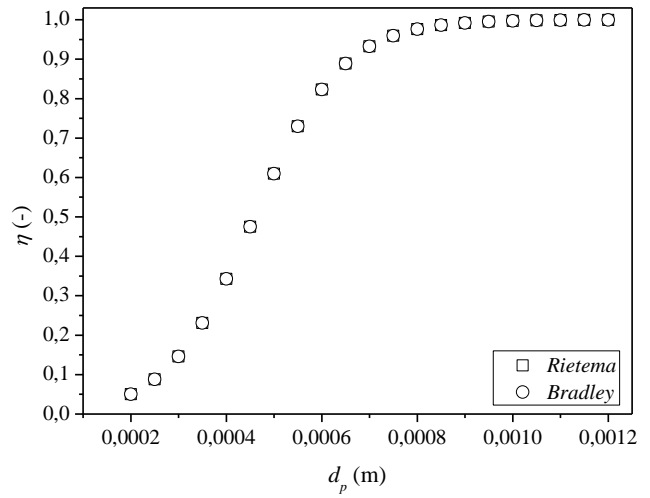

Figura 5 (d) - Eficiência em função do diâmetro de partícula.

As curvas das Figuras 5 (a, b e d) mostram que o aumento nos valores da $Q, \rho_{s}$ e $d_{p}$ promovem um aumento no valor da $\eta$ para ambos os hidrociclones projetados. Este resultado condiz com o esperado fisicamente, visto que o aumento dessas variáveis promove um aumento na força centrípeta e, consequentemente, uma elevação na eficiência de separação. Para o aumento no valor da $C_{v}$ é verificado na Figura 5 (c) uma diminuição no valor da $\eta$. Novamente, este fenômeno esta de acordo com o esperado. Segundo Massarani (2002) a concentração de sólido no efluente é inversamente proporcional à eficiência, pois a velocidade terminal da partícula sofre uma redução devido à presença de outras partículas. Sendo assim, a concentração de sólido influencia substancialmente na velocidade de uma partícula, fazendo com que a eficiência de coleta do equipamento sofra uma redução. Um aspecto importante também observado nas curvas das Figuras 5 (a - d) é a faixa granulométrica dos sólidos contidos no lodo estudado. Como o diâmetro das partículas é relativamente alto, maior que $100 \mu \mathrm{m}$ (Mihelcic e Zimmerman; 2012), os dois tipos de hidrociclone operam de maneira muito semelhante e apresentam valores na eficiência individual de coleta muito próximos um do outro.

Na Figura 6 é mostrada a análise da perda de carga nos hidrociclones $(\Delta P)$ projetados em função da vazão de alimentação do lodo $(Q)$.

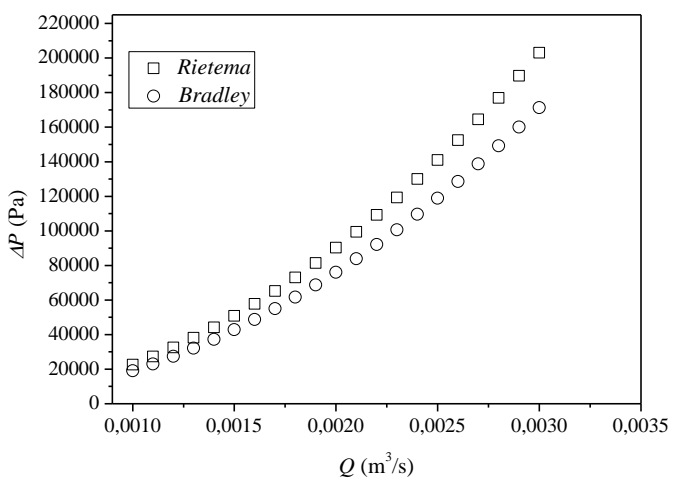

Figura 6 - Perda de carga nos hidrociclones projetados em função da vazão de alimentação do lodo. 
Observa-se na Figura 6 que a $\Delta P$ sofre um aumento significativo com o aumento da $Q$ para ambos os hidrociclones projetados. Esse fato, aliado aos dados da Figura 5 (a), mostra que aumentando-se o valor de $Q$ aumenta-se a $\eta$, porém aumenta-se também a $\Delta P$ dos hidrociclones. Outro aspecto importante observado nas curvas da Figura 6 foi que o aumento no valor da $\Delta P$ em função da $Q$ foi mais pronunciado para o hidrociclone da família Rietema que possui um valor de $D_{c}$ menor.

\section{CONCLUSÃO}

Levando em conta a importância financeira da indústria têxtil e também a cobrança da legislação ambiental para o uso correto dos meios naturais e ao descarte do efluente, os resultados apontam que os hidrociclones do tipo Rietema e Bradley apresentam uma boa eficiência na desidratação dos lodos provenientes do processo de lavagem de lãs na indústria têxtil. Também conclui-se que, apesar de ambos os hidrociclones projetados apresentarem uma boa eficiência de separação, o hidrociclone do tipo Rietema é o mais adequado para espessamento de lodo provido da indústria têxtil analisada por apresentar uma menor quantidade de líquido saindo no underflow.

\section{REFERÊNCIAS}

AZEVEDO, J.J.R. Poluição pela indústria têxtil. UC. Analise de Sistemas Ambientais Tópico: Solos. Escola Superior Agraria de Ponte de Lima.

CREMASCO, M.A. Operações unitárias em sistemas particulados. São Paulo: Editora Blucher, 2012.

FOUST,A.S.; WENZEL,L.A.; CLUMP,C.W.; MAUS,L.; ANDERSEN,L.B. Princípios das operações unitárias. Editora Guanabara Dois S.A., Segunda Edição, 1982.

FLORES, C.G. Análise de recuperação da lanolina proveniente do beneficiamento da lã de ovinos. TCC curso de Eng.Quim . Universidade Federal do Pampa, 2014.

SILVA. D.O. Otimização da separação sólido-líquido em hidrociclones mediante modificações geométricas. Tese de doutorado. Universidade Federal de Uberlândia. Programa de Pós Graduação em Engenharia Química. 2012.

TUNAY, O. Color Removal From Textile Wastewaters. Water Science \& Technology. Vol.34, $\mathrm{n}^{\mathrm{o}}$ 1,1996

MASSARANI, G. Fluidodinâmica em sistemas particulados. Rio de Janeiro: Editora Papers Serviços Editoriais, 2002.

MIHELCIC, J.R.; ZIMMERMAN, J.B. Engenharia ambiental: fundamentos, sustentabilidade e projeto. Rio de Janeiro: Editora LTC, 2012.

AGRADECIMENTOS: os autores deste trabalho agradecem a UNIPAMPA/Bagé e a CAPES pela concessão da bolsa. 